\title{
'Can you hear me? Are you there?': student engagement in an online environment
}

\section{Karen Symons}

De Montfort University, UK

Keywords: student engagement; invisible learners; active learning; Covid-19.

\section{The challenge}

With teaching moving from face-to-face to remote this year, I have struggled with the feeling of 'teaching into the void'. Teaching mathematical content has been particularly challenging, as communicating complex mathematical notation remotely is not easy. I have found myself continually wondering what students are doing 'behind their screens' are they engaging with my sessions and if so, how?

The concept of 'student engagement' is important, as it is based on the belief that learning improves when students are fully involved in their learning (Deslauriers, 2019). This engagement often manifests itself in student participation. Given the importance of active learning (Freeman et al., 2014; Petty, 2021) my goal as a teacher is to enable students to actively explore, engage with and talk about maths. But what does this look like in the online world? How can this be seen or measured?

\section{The response}

In July 2020, I attended a Teaching and Learning Maths Online (TALMO) event, at which Holmes reported that 'in Maths workshops, research findings show that there are high participation rates - even if students are not sharing their answers' (Holmes et al., 2020). This statement filled me with hope, and I decided to investigate this finding by exploring the levels of engagement in my weekly $1^{\text {st }}$ year Engineering Maths support workshops, at which attendance is optional. I had three measures of engagement available to me: 
- Attendance data

- Chat box comments

- Feedback questionnaire

\section{Attendance data}

Figure 1 below shows that the numbers of students choosing to attend the online workshops this year compared to face-to-face last year has increased. This pattern, with the exception of Week 7 , has continued throughout the year.

Figure 1. Attendance at Engineering workshops.

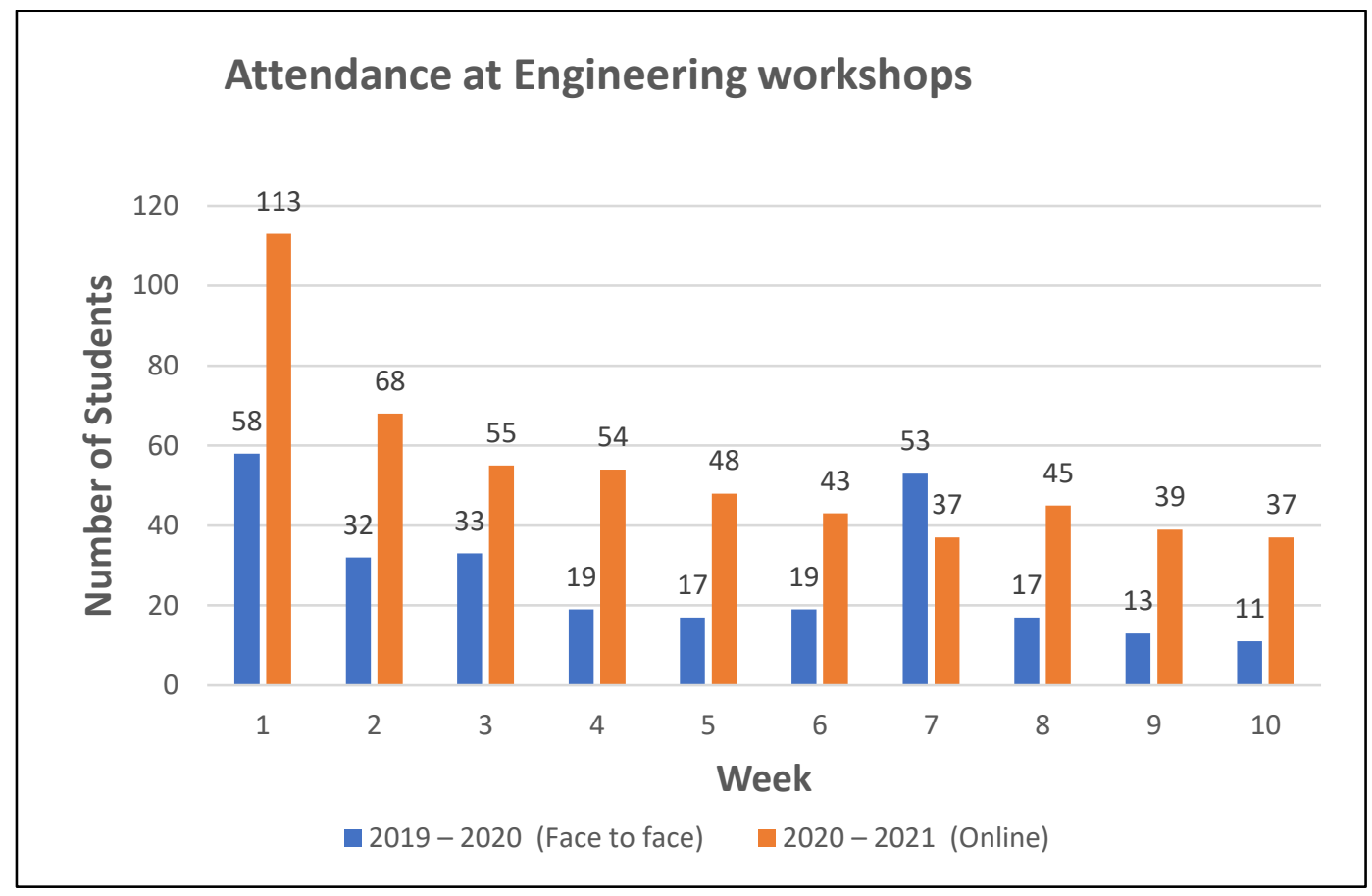

This could be due to a number of reasons, such as: attending online is more convenient; students are keen for 'live' contact; and students value having the opportunity to benchmark themselves against others. However, although attendance data does offer some measure of engagement, purely in terms of being present, it does not offer any insight into what students are doing once they have arrived. Therefore, in order to gain a greater understanding, I analysed the comments made in the chat box. 


\section{Chat box analysis}

I analysed the comments from Week 3. They were categorised into three types, as shown in Table 1:

Table 1. Categories of chat box comments.

\begin{tabular}{|l|l|}
\hline $\begin{array}{l}\text { Type of Comment } \\
\text { Hello/bye/feedback }\end{array}$ & $\begin{array}{l}\text { Percentage of comments, \% } \\
\text { (total = 101) }\end{array}$ \\
\hline $\begin{array}{l}\text { Engagement with } \\
\text { mathematical content }\end{array}$ & 56 \\
\hline $\begin{array}{l}\text { Miscellaneous* } \\
\text { *For example: "I can't hear" (IT issues); "Where can I find the recording of the main lecture?" (questions } \\
\text { about the rest of their course) }\end{array}$ & 9 \\
\hline
\end{tabular}

As well as considering the number of comments, another important aspect is the number of students who made these comments. We do not want one student to comment 101 times! Analysis of the chat showed that $73 \%$ of the students contributed to the total number of comments, and, more importantly, out of these contributors, $74 \%$ commented on mathematical content. This was largely consistent with other weeks, although the percentage of comments related to maths increased (for example, Week 10, 72\%). These high participation rates were very reassuring; engagement was a lot higher than it felt when teaching. Furthermore, a few chat box comments such as '[l] get it now', 'Same here' and 'And me' were from students who did not visibly participate in the session. This prompted me to further consider 'invisible learners' - or 'lurkers' as they are sometimes referred to (Honeychurch et al., 2017).

\section{Feedback form}

Other than putting on microphones and speaking, and writing in the chat box, what else were students doing? Were they doing any maths? Did they have the necessary resources, such as calculators? Therefore, in Week 9, I carried out a survey (See Figure 2) to give me further insight into levels of engagement and 'invisibility'. 
Figure 2. In which ways do you engage with these workshops? (32 responses)

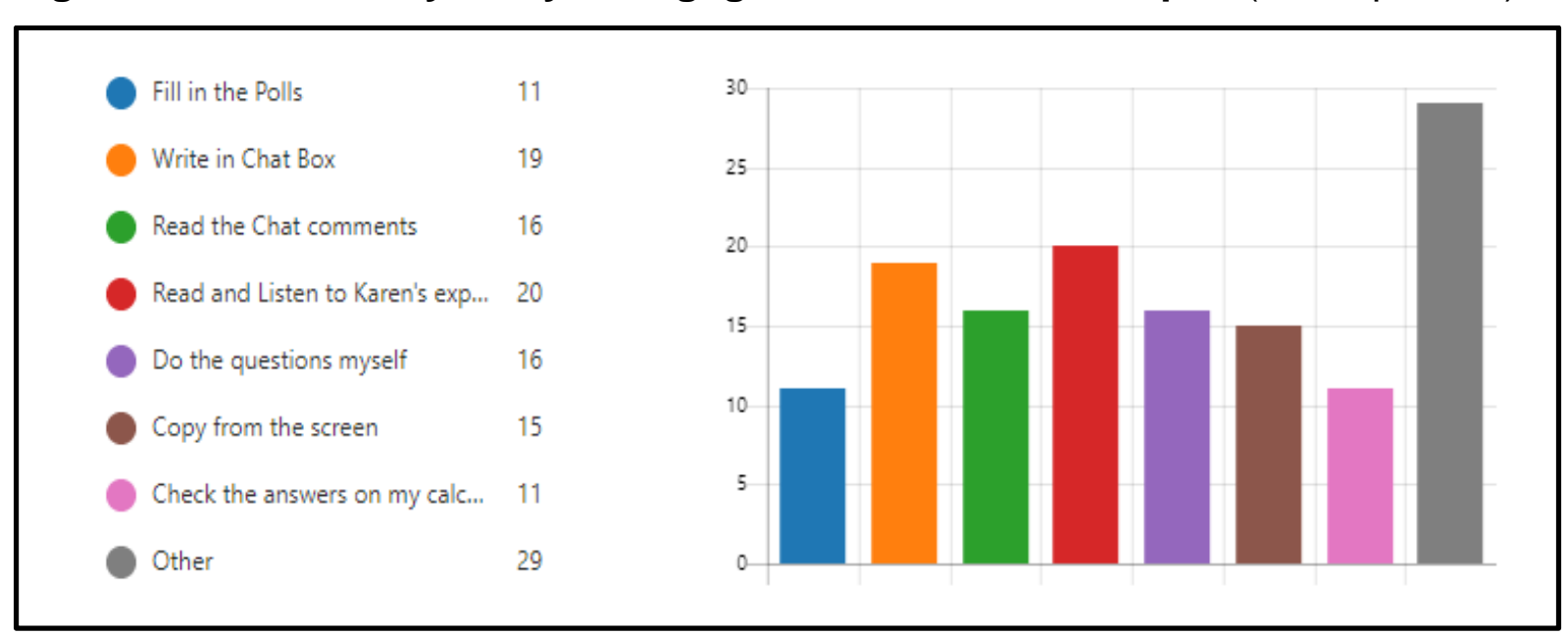

Note: 'Other' - included working through key resources prior to the session, pre-watching short videos and re-visiting the work again after the session.

There was a notable difference in the depth in which students engaged. It ranged from:

\section{Student A}

"Have a go at the key resource", "Pre-watch the videos ","Read the chat comments", "Read and listen to the teacher's explanations", "Do the questions myself", "Copy from the screen", "Check the answers on my calculator", "Go through it again"

to:

\section{Student B}

"Read and Listen to the teacher's explanations", "Check the answers on my calculator".

But what is interesting is that, for both of these students, there would have been no visible participation. This supports Holmes' statement that 'there are high participation rates even if students are not sharing their answers' (Holmes et al., 2020).

\section{Recommendations}

I have used the analogy of an iceberg (See Figure 3) to summarise my findings and thoughts: 
Figure 3. The iceberg of engagement.

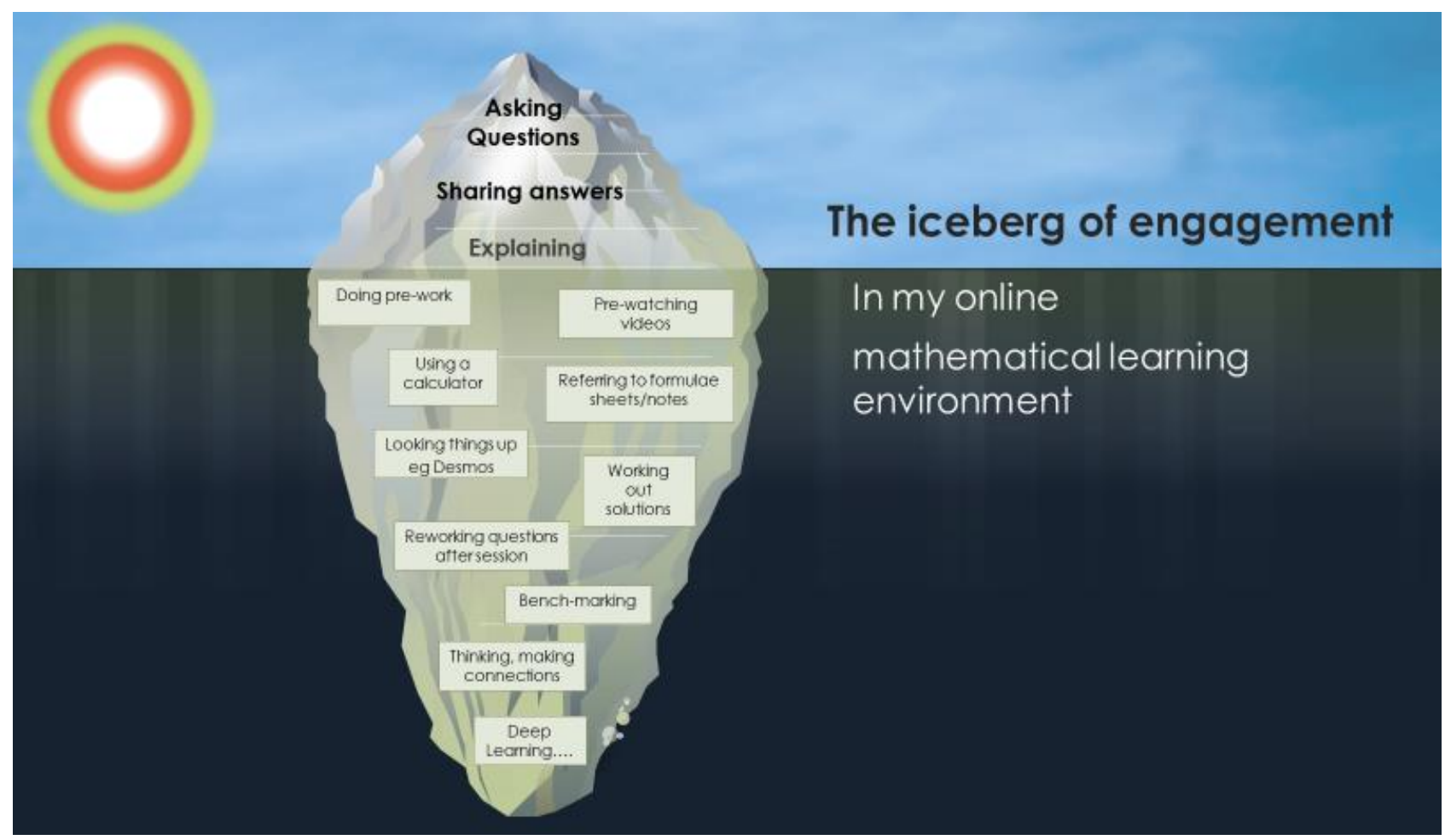

As teachers, we only ever see the tip of the iceberg, whatever the teaching environment. Online delivery can result in this tip being diminished, but it is important to realise that 'beneath the surface' or 'behind the screens' considerable engagement and learning can be taking place. From this I have drawn five recommendations to take forward in my teaching:

1. Explicitly expect and encourage engagement, and then you will be more likely to get it. It helps to use names to personalise things, to deflect questions back to other students to answer, and to foster an environment in which getting an answer 'wrong' is valuable.

2. Acknowledge and reward each attempt to interact and relate this to how beneficial this is for learning; praise every interaction.

3. Create interactive learning materials to ensure that there are opportunities for interaction in the session.

4. Use timers and build 'doing' time into each session, as this is necessary for all the 'under the surface' activities to be able to take place. 
5. Cut down content to give time to students to process and 'do'; it is not about what is 'covered', it is about the learning that takes place.

\section{References}

Deslauriers, L., McCarty, L.S., Miller, K., Callaghan, K. and Kestin, G. (2019) 'Measuring actual learning versus feeling of learning in response to being actively engaged in the classroom', Proceedings of the National Academy of Sciences, 116(39), pp.19251-19257. Available at: https://doi.org/10.1073/pnas.1821936116 (Accessed: 4 September 2021).

Freeman, S., Eddy, S.L., McDonough, M., Smith, M.K., Okoroafor, N., Jordt, H. and Wenderoth, M.P. (2014) 'Active learning increases student performance in science, engineering and maths', Proceedings of the National Academy of Sciences, 111(23), pp.8410-8415. Available at: https://doi.org/10.1073/pnas.1319030111 (Accessed: 4 September 2021).

Holmes, H. et al. (2020) 'Encouraging online student participation'. TALMO (Teaching and Learning Mathematics Online), 10 July. Available at: https://www.youtube.com/watch?v=GWdZRWvU1CY (Accessed: 2 June 2021)

Honeychurch, S., Bozkurt, A., Singh, L. and Koutropoulos, A. (2017) 'Learners on the periphery: lurkers as invisible learners', European Journal of Open, Distance and eLearning, 20(1), pp.192-212. Available at: https://doi.org/10.1515/eurodl-2017-0012 (Accessed: 4 September 2021).

Petty, G. (2021) Active learning. Available at: https://www.geoffpetty.com/forteachers/active-learning (Accessed: 7 June 2021)

\section{Author details}

Karen Symons is a Senior Lecturer in Mathematics Support at De Montfort University, Leicester, UK. She has been an educator for over 30 years, in many different sectors of 
education, and her teaching is underpinned by research-informed good educational practice and her own reflective practice. 